\title{
Representações sociais de violência e estratégias de ensino utilizadas por docentes de graduação em enfermagem
}

\author{
Daniella Yamada Baragatti ${ }^{1}$, Marcio Cristiano de Melo $^{2}$, Ana Carine Arruda Rolim ${ }^{3}$, \\ Eliete Maria Silva ${ }^{4}$, Zeyne Alves Pires Scherer ${ }^{5}$
}

\footnotetext{
${ }^{1}$ Enfermeira, Doutora em Enfermagem.

Enfermeira da Estratégia Saúde da Família da Prefeitura Municipal de Campinas/SP.

Campinas, SP, Brasil. E-mail:

danybaragatti@gmail.com.

${ }^{2}$ Enfermeiro, Mestre em Saúde Coletiva. Discente do Programa de Pós-Graduação em Saúde Coletiva da Faculdade de Ciências Médicas da Universidade Estadual de Campinas, nível Doutorado. Campinas, SP, Brasil. E-mail: enf.marciomelo@gmail.com.

${ }^{3}$ Enfermeira, Mestre em Saúde Coletiva. Discente do Programa de Pós-Graduação em Saúde Coletiva da Faculdade de Ciências Médicas da Universidade Estadual de Campinas, nível Doutorado. Campinas, SP, Brasil. E-mail: anacarine.rolim@hotmail.com.

${ }^{4}$ Enfermeira, Doutora em Enfermagem. Professora Associada da Faculdade de Enfermagem da Universidade Estadual de Campinas. Campinas, SP, Brasil. E-mail: emsilva@unicamp.br.

${ }^{5}$ Enfermeira, Doutorado em Enfermagem Psiquiátrica. Professora Associada da Escola de Enfermagem de Ribeirão Preto da Universidade de São Paulo. Ribeirão Preto, SP, Brasil. E-mail: scherer@eerp.usp.br.
}

Recebido: 03/10/2016.

Aceito: 18/06/2017.

Publicado: 27/11/2017.

Como citar esse artigo:

Baragatti DY, Melo MC, Rolim ACA, Silva EM, Scherer ZAP. Representações sociais de violência e estratégias de ensino utilizadas por docentes de graduação em enfermagem. Rev. Eletr. Enf. [Internet]. 2017 [acesso em: ____19:a40. Disponível em: http://dx.doi.org/10.5216/ree.v19.43557.

\begin{abstract}
RESUMO
Estudo descritivo exploratório, qualitativo, cujo objetivo foi descrever as representações sociais da abordagem do tema da violência e das estratégias de ensino utilizadas por docentes de graduação em enfermagem de duas instituições de ensino superior públicas. Para a coleta dos dados foram utilizadas pesquisa documental, observação sistemática e entrevista semiestruturada. Os dados foram submetidos à análise por meio da técnica do Discurso do Sujeito Coletivo. Os docentes reconhecem a importância de a violência ser trabalhada na graduação descrevendo que, apesar de nem sempre aparecer no currículo formal, o assunto surge informalmente na formação acadêmica. As representações sociais de violência nos discursos docentes aparecem como manejo de pacientes agressivos e violência institucional no ambiente acadêmico. As estratégias pedagógicas descritas são ativas e emancipadoras. Para que haja formação de enfermeiros capacitados para lidar com a violência, o ensino deve ir além das questões biológicas, contemplando discussões sobre as vivências dos alunos.
\end{abstract}

Descritores: Violência; Currículo; Docentes; Educação em Enfermagem.

\section{INTRODUÇÃO}

A violência interpessoal é um problema que acompanha a história da humanidade apresentando-se sob diversas formas como, por exemplo, os maus-tratos infantis, as violências juvenil, conjugal, sexual e o abuso de idosos ocorrendo dentro ou fora de casa, como escolas, locais de trabalho, prisões e asilos. Trata-se de uma questão 
reconhecida por manter comunicação com todas as áreas do conhecimento humano devido ao seu caráter transversal e sua inserção em discussões relacionadas ao setor saúde em virtude das graves repercussões na saúde individual e coletiva dos indivíduos, sendo considerada um grave problema de saúde pública ${ }^{(1)}$.

Ao considerar que se trata de fenômeno complexo, a violência é reafirmada e assumida pela Organização Mundial da Saúde (OMS) como uso intencional da força física ou do poder, real ou em ameaça, que resulte ou tenha possibilidade de resultar em lesão, morte, dano psicológico, deficiência de desenvolvimento ou privação ${ }^{(1)}$.

A definição associa a intencionalidade com a prática do ato propriamente dito, independentemente do resultado produzido. Tais atos derivam de uma relação de poder, incluindo ameaças e intimidações. "O uso da força física ou do poder" compreende a negligência e todos os tipos de abuso físico, sexual e psicológico, bem como o suicídio e outros atos de auto-abuso ${ }^{(1)}$.

A violência se situa no âmbito eminentemente humano, sendo um fenômeno sobre o qual existe responsabilidade dos sujeitos. Apresenta profundo enraizamento nas estruturas sociais, econômicas e políticas, bem como nas consciências individuais, sendo portanto possível sua análise, compreensão, intervenção e superação(2).

O setor saúde busca ir além de sua função tradicional curativa de cuidar dos agravos físicos e emocionais gerados pelos conflitos sociais, sendo de fundamental importância a definição de medidas preventivas e de promoção à saúde, o que inclui a abordagem à violência ${ }^{(3-4)}$.

Os currículos dos cursos de graduação em enfermagem devem contemplar essa temática refletindo sobre a violência como problema de saúde pública, pois a atuação do profissional é influenciada pelo processo de formação do enfermeiro, uma vez que seus conhecimentos, habilidades e competências constituem-se a partir da graduação. Assim, o processo de formação pode gerar consequências positivas ou negativas, influenciando na qualidade da assistência em saúde prestada ${ }^{(5)}$.

O processo de ensinar exige compreender que a educação é uma forma de intervenção no mundo, pois os conteúdos bem ou mal ensinados e/ou aprendidos podem resultar na reprodução da ideologia dominante ou no seu desmascaramento ${ }^{(6)}$. Assim, a atuação dos profissionais de saúde, em especial dos enfermeiros, nos casos de violência pode estar relacionada à forma como tal conteúdo é abordado pelos docentes na graduação.

Ainda hoje, o processo de ensino-aprendizagem na saúde tem como base o professor como detentor do saber, que segue um modelo curricular tradicional de ensino com transmissão de conhecimentos pelo docente, o que resulta em lacunas nos espaços de formação, não comportando toda a discussão e instrumentalização necessárias ao favorecimento do processo ${ }^{(7)}$.

A formação dos enfermeiros deve seguir o previsto pelas Diretrizes Curriculares Nacionais para os cursos de graduação, nas quais é previsto que o profissional formado, além de ser capaz de intervir nas principais situações de saúde-doença, deve ter responsabilidade social, identificando as dimensões biopsicossociais dos fenômenos ${ }^{(8)}$. 
Ao pensar nos currículos de graduação em enfermagem, nas atuais políticas e discussões sobre as construções de Projetos Político-Pedagógicos (PPP) voltados para as necessidades sociais da população, o tema violência deve ser analisado e discutido. Trata-se de uma questão da práxis sociopolítica, que se realiza como parte da história humana e social, independentemente de qual seja sua especificidade ${ }^{(9)}$.

Assim sendo, o objetivo deste estudo é descrever as representações sociais da abordagem do tema da violência e das estratégias de ensino utilizadas por docentes de graduação em enfermagem de duas instituições de ensino superior públicas.

\section{MÉTODOS}

Pesquisa qualitativa descritiva e exploratória cujo campo de estudo foram dois cursos de graduação em enfermagem de duas instituições públicas de Ensino Superior localizadas no estado de São Paulo.

Os sujeitos deste estudo foram todos os responsáveis por ministrar disciplinas que contemplavam a abordagem da violência em seus planos de ensino, totalizando 15 docentes. Os critérios de inclusão foram: serem docentes atuantes nas instituições que, entre junho e setembro de 2012, ministrassem as disciplinas cujos programas continham a palavra "violência" ou correlatos (abuso, agressivo, agressividade, agressão, vítima, vitimização, violento, violenta, trauma, negligência, luta, poder, briga, lesão, ferir, bater, drogas, provocação, provocações, mutilação, estupro, coação, perpetração, perpetrador, perpetrada, abandono, espancar, espancada). Os termos selecionados para a pesquisa foram escolhidos por possibilitarem a busca pela abordagem da violência interpessoal nos currículos de graduação das duas instituições, tendo como base as palavras mais frequentes no Relatório Mundial sobre Violência e Saúde ${ }^{(1)}$.

Para a coleta de dados foram utilizadas técnicas de pesquisa documental, entrevista semiestruturada e observação sistemática para a coleta de dados.

A pesquisa documental foi realizada por meio da consulta aos programas de todas as disciplinas dos cursos de graduação em enfermagem previstas nos PPP. Elaborou-se um protocolo de pesquisa, contemplando as informações referentes a aspectos de identificação da disciplina, objetivos, ementa, programa e conteúdo programático, referências, tempo de existência da disciplina, aparecimento do termo "violência" ou correlatos e estratégias de ensino descritas para abordagem da violência.

O roteiro da entrevista foi composto por questões previamente elaboradas pelos pesquisadores e submetido à apreciação de três juízes. Essa forma de obter os dados permitiu o livre discurso e, ao mesmo tempo, o delineamento da conversa buscando manter a entrevista condizente com os objetivos da investigação.

Este artigo se reporta, especificamente, aos dados obtidos por meio dos tópicos da entrevista semiestruturada: "Como o(a) Sr(a) trabalha o tema violência com os alunos?" e "Quais são as estratégias utilizadas para abordar a violência?". O tempo de aplicação de cada entrevista variou de 40 minutos a duas horas e 30 minutos, em sala reservada e horários combinados. Todas as entrevistas foram gravadas e transcritas. 
Para a organização dos dados utilizou-se a técnica do Discurso do Sujeito Coletivo (DSC) ${ }^{(10)}$, que consiste na reunião de um só discurso-síntese por meio de vários discursos individuais emitidos como resposta a uma mesma questão de pesquisa por sujeitos equivalentes social e institucionalmente ou que fazem parte de uma mesma cultura organizacional e de um grupo social homogêneo.

Para se chegar ao DSC, o material empírico foi analisado utilizando-se as seguintes operações: 1) destaque dos trechos das transcrições que melhor descreviam o conteúdo do discurso, identificando-se as Expressões-chave (ECH); 2) identificação das Ideias Centrais (IC) das respostas dos diferentes indivíduos, reconhecendo-se semelhanças e complementaridades entre elas; 3) agrupamento das IC e ECH semelhantes que deu origem ao DSC, que é um discurso-síntese redigido na primeira pessoa do singular ${ }^{(9)}$.

Como referencial teórico para a análise das entrevistas utilizou-se a Teoria das Representações Sociais (TRS), por meio da qual o pesquisador pode captar a interpretação da realidade dos participantes do grupo que pretende conhecer, o que possibilita a compreensão de suas atitudes, crenças, valores, opiniões e conhecimentos frente à diversas temáticas ${ }^{(11)}$, dentre elas a violência.

A observação sistemática consistiu na anotação em caderno próprio das impressões pessoais e observações realizadas antes, durante e depois de cada entrevista durante a coleta de dados, abrangendo todo o processo.

O projeto de pesquisa foi aprovado pelo Comitê de Ética em Pesquisa (parecer no 158/2011). Todos os participantes assinaram o Termo de Consentimento Livre e Esclarecido (TCLE).

\section{RESULTADOS E DISCUSSÃO}

Do total de 15 docentes entrevistados, 14 eram do sexo feminino e um masculino. Na instituição I foram entrevistados cinco docentes e na instituição II foram 10 docentes. A maior parte dos entrevistados em ambas as instituições estava na faixa etária entre 51 e 60 anos (46,6\%). Em relação à formação, um dos entrevistados é pedagogo, os demais são enfermeiros. Todos os entrevistados possuíam como titulação mínima o Doutorado, com regime de trabalho de dedicação exclusiva.

$\mathrm{Na}$ instituição I o termo violência ou correlatos foram incluídos nos programas das disciplinas: "Cuidados em saúde mental”, "Educação para a saúde", "Saúde e segurança no trabalho de enfermagem", "Educação/orientação sexual nas escolas" e "O uso e abuso de álcool e drogas: visão geral".

$\mathrm{Na}$ instituição II, os docentes eram responsáveis pelas disciplinas “Assistência de enfermagem na saúde da criança e do adolescente I", "Assistência de enfermagem à saúde da mulher" e "Processo de cuidar em enfermagem psiquiátrica", nas quais o termo violência ou correlatos foram encontrados.

Os DSC são apresentados em três temas reunidos de acordo com as categorias construídas a partir das Ideias Centrais (IC) que emergiram dos discursos que expressavam a Representação Social, a partir do número de Expressões Chave $(\mathrm{ECH})$ dos docentes entrevistados, identificadas pela letra D. Para melhor visualização e entendimento optou-se pela apresentação disposta em Quadros 1, 2 e 3 apresentados a seguir. 
Quadro 1: Discurso-síntese sobre a abordagem da violência na teoria e na prática docente em cursos de graduação em enfermagem. Ribeirão Preto, SP, Brasil, 2012.

\begin{tabular}{|c|c|}
\hline \multicolumn{2}{|r|}{ Tema 1: Organização curricular da abordagem da violência } \\
\hline Ideia Central & Discurso do Sujeito Coletivo \\
\hline $\begin{array}{c}\text { A centralidade teórica no } \\
\text { currículo - três ECH (D7, } \\
\text { D14, D15) }\end{array}$ & $\begin{array}{l}\text { Uso aula expositiva com conteúdo teorizante, trago um pouco do conceito de violência. Uma coisa } \\
\text { que chama muito a atenção deles são as imagens da aula, lembrá-los de que, quando a gente não } \\
\text { vê isso, não quer dizer que a violência não exista. Tem um pouco do conceito, sinais e sintomas que } \\
\text { a gente pode encontrar na criança, trago um pouco de dados de quem é o agressor, de quem é a } \\
\text { criança que está mais vulnerável à violência. Eu começo a aula com um filme, por fim a gente } \\
\text { sempre discute um caso, eu sempre enfatizo com eles a importância de que eu não preciso ter } \\
\text { certeza para denunciar, eles fizeram prova ontem sobre violência. }\end{array}$ \\
\hline $\begin{array}{c}\text { A vivência prática e a } \\
\text { curiosidade discente - } \\
\text { seis ECH (D4, D6, D8, D10, } \\
\text { D12, D13) }\end{array}$ & $\begin{array}{c}\text { Às vezes, muitas vezes na verdade, infelizmente, eu acabo abordando esse tema na prática, } \\
\text { principalmente no caso da disciplina de saúde da criança. Então eu acabo tendo a experiência de } \\
\text { falar com o aluno a respeito desse assunto por ter encontrado uma criança que tenha sofrido esse } \\
\text { mal. Através de discussões do tema, colocação de experiências de cada um, ou seja, eu trabalho } \\
\text { localmente, durante o estágio, quando alguém fala de alguma violência sofrida a gente aponta, ou } \\
\text { eu faço uma orientação sobre a ação social, o controle social, que são os caminhos [para lidar com } \\
\text { o problema]. }\end{array}$ \\
\hline
\end{tabular}

Quadro 2: Discurso-síntese sobre o a representação social do que é violência abordada nos currículos de graduação, segundo os docentes entrevistados. Ribeirão Preto, SP, Brasil, 2012.

\begin{tabular}{|c|c|}
\hline \multicolumn{2}{|r|}{ Tema 2: O que é a violência abordada nos currículos de graduação? } \\
\hline Ideia Central & Discurso do Sujeito Coletivo \\
\hline $\begin{array}{c}\text { O manejo de pacientes } \\
\text { agressivos - três ECH (D2, } \\
\text { D5, D12) }\end{array}$ & $\begin{array}{l}\text { A disciplina é toda contextualizada entre teoria e prática: teoria na terça-feira à tarde, e na sexta } \\
\text { eles passam o dia no Hospital das Clínicas, na enfermaria de psiquiatria. Nessa questão teórica tem } \\
\text { o manejo do paciente agressivo, tipos de contenção, e eu faço muita prática, faço todo esse } \\
\text { manejo, todo fundamentado na questão do relacionamento interpessoal terapêutico, que é com o } \\
\text { que eu trabalho. Apoio teórico para uma posição mais humanista, junto com os docentes da } \\
\text { medicina, junto com os alunos, pois sobre o relacionamento interpessoal, se você tiver uma boa } \\
\text { [relação de] confiança ele [o paciente] não vai te agredir, ele vai te respeitar. }\end{array}$ \\
\hline $\begin{array}{c}\text { Violência institucional no } \\
\text { ambiente acadêmico - } \\
\text { cinco ECH (D4, D6, D10, } \\
\text { D12, D15) }\end{array}$ & $\begin{array}{l}\text { Também quando passo pelos conceitos de acidentes, por exemplo, assédio e mesmo dos } \\
\text { adoecimentos, nas aulas expositivas informo eles [os estudantes] que isso não pode acontecer, } \\
\text { caso aconteça é uma situação de violência, dou algumas definições do que seja essa violência } \\
\text { institucional que pode acontecer e com alguns exemplos práticos de acidentados, isso caracterizo } \\
\text { bem como uma situação de violência do trabalho. E faço visitas em empresas, então essa parte } \\
\text { prática depois eu comento quando os alunos vão para a sala de aula e coloca isso, que isso é um } \\
\text { episódio de violência com o trabalhador. Às vezes dou exemplos da própria instituição aqui, é aula } \\
\text { dialogada, eles começam a falar de professores contra eles durante as discussões. }\end{array}$ \\
\hline
\end{tabular}

Quadro 3: Discurso-síntese sobre as estratégias pedagógicas utilizadas por docentes para abordar a violência. Ribeirão Preto, SP, Brasil, 2012.

\begin{tabular}{|c|c|}
\hline Ideia Central & Discurso do Sujeito Coletivo \\
\hline $\begin{array}{c}\text { O uso de metodologias } \\
\text { ativas e emancipadoras - } \\
\text { cinco ECH (D4, D6, D10, D12, } \\
\text { D13) }\end{array}$ & $\begin{array}{l}\text { Formalmente, na disciplina tem uma carga horária [em] que faço como se fosse uma mesa } \\
\text { redonda, um painel. Não só comigo, convido um profissional do Centro de Referência no } \\
\text { atendimento de mulheres vítimas de violência sexual, daí a gente conversa sobre isso, debate. } \\
\text { Tem o livro que tem um capítulo sobre violência, discute situações e exemplos de jornais, isso do } \\
\text { ponto da teoria. Na classe tento extrair de cada um as suas dificuldades e a gente problematizar, } \\
\text { através de dinâmicas, uma hora faço debates, tempestade cerebral, teatro, tentando } \\
\text { problematizar e em conjunto buscar solução para os problemas. Eu passo um vídeo, muito bom, } \\
\text { muito interessante sobre a violência sexual, e discuto essa questão e conversa sobre o assunto, e } \\
\text { [há] exposição dos próprios alunos nos seminários. Também converso sobre essas experiências } \\
\text { reais que elas [as estudantes] têm, é uma estratégia que mistura um pouco de vivência junto. }\end{array}$ \\
\hline
\end{tabular}

Sobre a organização curricular da abordagem da violência, obteve-se dois discursos síntese apresentados no Quadro 1. No primeiro, há a representação social de que a abordagem da violência é 
centrada somente na parte teórica do currículo. Já na segunda a representação social é de que a violência é abordada também nas práticas discentes, quando a temática aparece nos estágios.

Para alguns autores os estudantes não estão preparados para entender de maneira ampliada a ocorrência, por exemplo, da violência por parceiro íntimo e suas implicações sociais, econômicas e de saúde, sendo que a abordagem do tema no currículo é de extrema importância para o desenvolvimento desta competência. Visando uma eficaz estratégia educacional curricular, os alunos devem ter contato com o tema não somente na teoria, mas também na prática, em instituições como, por exemplo, organizações comunitárias que lidem com a prevenção da violência ${ }^{(12)}$.

A transformação de algo não familiar em algo familiar constitui a razão da formação das representações sociais. O familiar é o que nos é conhecido, o senso comum, salvo de qualquer risco, atrito ou conflito, confirmando nossas crenças, reforçando nossa tradição. O não familiar é o que nos causa conflito, é o desconhecido ${ }^{(11)}$. Frente a isso, nas universidades estudadas, a violência não aparece nos planos de ensino da prática de maneira formal, mas se revela de maneira informal trazida pelos alunos. Assim, o surgimento do assunto no cotidiano da prática se torna fundamental para que haja discussões sobre o tema e melhor preparo dos docentes para abordar e lidar com o fenômeno da violência ${ }^{(12-13)}$.

Notou-se que para alguns docentes ainda há a representação social de que currículo é o que se apresenta por escrito, de maneira teórica. Apesar das definições contidas nas Diretrizes Curriculares Nacionais de Enfermagem, o currículo vai além do que está prescrito nas legislações, uma vez que é também construído pela tradição cultural e pelo que acontece na prática, não só a partir de referenciais teóricos, mas por meio das experiências dos sujeitos participantes ${ }^{(14)}$.

Na prática, os profissionais de saúde têm dificuldade em reconhecer uma situação de violência e prestar atendimento às vítimas, atribuindo tal dificuldade à formação profissional na graduação, que não aborda a temática de maneira adequada ${ }^{(13)}$. Em uma pesquisa americana, estudantes de diversas áreas da saúde, inclusive de enfermagem, prestaram atendimento à uma mulher com corte na mão devido à violência doméstica e somente $38 \%$ deles suspeitaram desta causa, o que sugere que o assunto deva ser melhor abordado no currículo ${ }^{(15)}$.

Se a violência é frequente nos diversos espaços sociais, é fundamental que haja discussões para que seja abordada de modo organizado e fundamentado nas atividades práticas de estágio, fonte de profundos debates entre docentes e alunos.

No Quadro 2 apresenta-se a representação social do que é violência abordada nos currículos de graduação, segundo os docentes entrevistados:

Quando questionados sobre como trabalham o tema violência com os alunos, os docentes expressaram seus conhecimentos sobre violência ancorados nas representações sociais dos abusos (físico, sexual, psicológico e negligência) a serem abordados nos cursos de graduação.

O primeiro discurso síntese demonstra a representação social de que abordar a violência no currículo é discutir sobre o manejo de pacientes agressivos. Para tal, esses docentes disseram mobilizar conceitos 
teóricos do relacionamento terapêutico centrado na pessoa, a posição humanista. A relação de ajuda se estabelece quando uma das partes procura promover na outra o desenvolvimento, o crescimento, a maturidade e uma maior capacidade de enfrentar a vida. Essas interações ocorrem entre mãe e filho, professores e alunos, enfermeiros e pacientes, entre outras, e as atitudes nessa relação podem favorecer ou inibir a pessoa que se pretende ajudar ${ }^{(16-17)}$.

Segundo a Organização Mundial de Saúde (OMS), a natureza dos atos violentos pode ser física, sexual, psicológica e envolvendo privação ou negligência ${ }^{(1)}$. É importante que todo ato violento, independente da natureza, seja abordado pelos docentes durante a graduação para que, ao se formar, o enfermeiro não se atente somente às manifestações de agressões físicas, que pode ser também a representação social deste grupo sobre o que é violência.

A segunda representação social sobre o que é a violência abordada nos currículos de graduação referese à violência institucional presente no ambiente acadêmico. Como se pode esperar que o aluno, enquanto profissional, tenha postura acolhedora e empática se nem sempre a postura do docente é esta? O professor é um modelo. Os docentes precisam refletir sobre o processo de ensino-aprendizagem, que não acontece somente por meio das apresentações e discussões teóricas, uma vez que a postura no dia a dia, diante dos alunos e colegas de trabalho, instiga reflexões e observações dos alunos, inspirando de maneira positiva ou não esse futuro profissional.

Nesse sentido, se faz importante refletir sobre as relações que se processam entre docentes e alunos no ambiente da universidade e os elementos que permeiam tal relação. Pode-se pensar na existência de um poder disciplinador quando há controle do comportamento através de normas para impor uma relação de utilidade, especialmente na docência para a saúde ${ }^{(18)}$, a abordagem da relação saber-poder ancorada na representação social do senso comum de que a escola é o espaço onde o poder disciplinar produz saber conferindo-Ihe autoridade.

Pesquisa sobre a manifestação da violência no ambiente universitário de acadêmicos de enfermagem corrobora este achado. Nela, os autores encontraram que, seja em sala ou em campo de estágio, as interações sofrem influências das diferenças de poder, sendo que há tendência à naturalização das ocorrências de violência. Os autores destacam ainda a importância de haver discussões com os docentes e alunos sobre a temática ${ }^{(19)}$.

A necessidade de discutir as relações entre docentes e alunos, incluindo as relações de poder que permeiam a estrutura universitária, se faz urgente e necessária para que o processo de aprendizagem não seja unilateral e não se dê permeado de autoritarismo. Para isso, pensar estratégias para abordar o tema é imprescindível, sendo que algumas destas são descritas no Quadro 3.

O uso de metodologias ativas e emancipadoras é uma representação social do pensamento coletivo desse grupo de docentes que reflete o preconizado pelas Diretrizes Curriculares de Enfermagem.

Nesta pesquisa os docentes citaram estratégias de ensino, tais como: filmes, leitura de textos, aulas teóricas (aula expositiva ou dialogada), seminários, discussões de casos clínicos e em grupo, dramatizações 
e tempestade cerebral. Refletir sobre a importância do incentivo para os alunos participarem ativamente das aulas torna-se cada vez mais um desafio didático para os docentes acostumados a uma educação tradicional, destacando que para tal é necessário que haja escolha das técnicas adequadas, dependendo do que se pretende ensinar e com quais objetivos ${ }^{(20-21)}$.

Em uma revisão integrativa, com o propósito de conhecer as estratégias de ensino mais utilizadas pelos cursos de graduação em enfermagem, os métodos mais citados foram os de simulação com bonecos de alta fidelidade e via WEB (World Wide Web) (19\%) seguida pela educação baseada em problemas (16\%) e estudo de caso (5\%). Os resultados diferem dos que encontramos, pois trata-se de análises relacionadas ao ensino em outros países ${ }^{(22)}$.

Outro estudo investigou, também por meio de revisão integrativa, pesquisas nacionais sobre as estratégias de ensino utilizadas pelos cursos de enfermagem. Nos trabalhos houve predominância de experiências de metodologias ativas aplicadas isoladamente em disciplinas ou atividades de ensino, sendo que tais experiências são motivadas por interesse pessoais. Assim, as metodologias mais encontradas foram a problematização (46\%), metodologias ativas (39\%), metodologias participativas (11\%) e aprendizagem baseada em problemas $(4 \%)^{(23)}$.

O método de trabalho em grupo, ou ensino socializado, tem como foco a integração com o meio social institucional e externo, o que visa o desenvolvimento da capacidade de interagir para que os alunos aprendam a expressar e defender suas ideias ${ }^{(20)}$. Nesta pesquisa, associado ao trabalho em grupo, foi citado o uso de painel definido como uma forma ativa de apresentar um tema.

Outro recurso utilizado pelos docentes foram discussões de casos clínicos. Os estudos de caso têm como principal benefício a adoção de uma abordagem orientada para perguntas e não baseada em soluções ${ }^{(20)}$. As discussões de casos clínicos, segundo os docentes deste estudo, são provenientes dos campos de estágio, quando os alunos têm contato com vítimas de violência ou trazem questões de violência da sua vivência e experiência pessoais.

Os docentes entrevistados referiram utilizar também os seminários em suas disciplinas para abordar o tema violência. O seminário é uma técnica muito usada nas universidades, porém questionada quanto à validade pedagógica pelos alunos que se percebem assumindo o papel do professor, sem apoio para a construção da proposta ${ }^{(24)}$.

O uso de estratégias de ensino-aprendizagem inovadoras e ativas por si só não garante que haja transformação do aluno em protagonista de seu aprendizado, bem como que o professor seja realmente um facilitador do processo, pois a aplicação dessas metodologias requer muito mais do que a sua simples utilização eventual.

Na fala dos docentes, há referência ao fato de que, mesmo o currículo institucional sendo descrito como não tradicional, na prática os docentes mantêm a base do ensino no modelo tradicional.

Neste sentido, uma pesquisa analisou os portfólios de estudantes de uma disciplina de um curso de graduação em enfermagem e encontrou que as competências esperadas não foram discutidas entre alunos 
e docentes nos momentos de avaliação, sinalizando a manutenção do modelo tradicional de ensino ${ }^{(25)}$. Em tempos de Diretrizes Curriculares que incentivam o uso de metodologias ativas, é preciso cuidado para que a utilização delas não faça parte somente do discurso dos docentes, diferindo da prática. Apesar dos textos oficiais apresentarem um discurso de valorização das competências, integrado e de flexibilidade, na prática pode assumir outros significados, podendo ser rejeitados ou ressignificados de acordo com o contexto em que se encontram ${ }^{(12)}$.

\section{CONCLUSÃO}

O tema da violência, nas duas universidades estudadas, aparece pouco e de maneira fragmentada e superficial nos currículos. Mesmo nas disciplinas em que os termos ou correlatos aparecem, muitas vezes o tema é abordado por apenas um docente e teoricamente, em uma aula de algumas horas e quase sempre ancorado nas representações sociais do senso comum qualificado pela agressão física. A abordagem do tema depende, portanto, da motivação individual de cada docente.

A abordagem do tema nos currículos está em processo de construção e, portanto, as instituições de ensino superior da área da saúde, e principalmente de enfermagem, devem ampliar as discussões sobre o assunto em suas atividades acadêmicas. Apesar de nem sempre aparecer de maneira formal e direta nos programas das disciplinas, a violência é vivenciada pedagogicamente nas práticas e nos estágios, quando os alunos têm contato direto com a população. É fundamental, pois, que haja discussões sobre o tema entre os docentes, bem como a organização de estratégias para melhor abordagem na graduação.

Assim, um modelo de ensino pautado nas questões biológicas, apesar de ser um dos aspectos importantes na construção da formação do futuro profissional de saúde, não abrangerá de forma suficiente toda a problemática da violência de modo a formar profissionais capacitados para lidar com ela.

A violência institucional também foi citada como algo vivenciado pelos alunos. Logo, as discussões sobre esse tipo de violência devem ser ampliadas, uma vez que sua ocorrência fundamenta-se nas relações de poder existentes no ambiente universitário.

Apesar das estratégias de ensino citadas pelos docentes constituírem-se ativas e emancipadoras, seria interessante realizar nova pesquisa com os alunos para conhecer a perspectiva dos mesmos sobre a temática.

Para atender às atuais demandas da sociedade é preciso uma ação de enfermagem com práticas alternativas ao modelo de ensino desenvolvido convencionalmente. A diminuição da violência é uma demanda da sociedade, sendo a atuação do enfermeiro integrada e articulada com a equipe multiprofissional fundamental no processo de mudança para o seu enfrentamento, o que deve ser estimulado desde o início do processo de formação desses profissionais.

\section{REFERÊNCIAS}


1. Krug EG, Dahlberg LL, Mercy JA. World report on violence and health [Internet]. Geneva: World Health Organization, 2002 [acesso em: 27 nov. 2017]. Disponível em:

http://www.who.int/violence_injury_prevention/violence/world_report/en/full_en.pdf.

2. Minayo MCS. Violência e Saúde. $1^{\text {a }}$ ed. Rio de Janeiro: Editora Fiocruz, 2006.

3. Minayo MCS. A inclusão da violência na agenda da saúde: trajetória histórica. Cien Saude Colet [Internet]. 2006 [acesso em: 27 nov. 2017];11(suppl):1259-67. Disponível em: http://dx.doi.org/10.1590/S1413-81232006000500015. 4. Minayo MCS. O desafio do conhecimento: pesquisa qualitativa em saúde. $13^{a}$ ed. São Paulo: Editora Hucitec, 2013.

5. Pires ADS, Souza NVDO, Penna LHG, Tavares KFA, D’Oliveira CAFB, Almeida CM. A formação de enfermagem na graduação: uma revisão integrativa da literatura. Rev Enferm UERJ [Internet]. 2015 [acesso em: 27 nov. 2017];22(5):705-11. Disponível em: http://dx.doi.org/10.12957/reuerj.2014.11206.

6. Freire P. Pedagogia da autonomia: saberes necessários à prática educativa. 43a ed. São Paulo: Paz e Terra, 2011. 7. Freitas DA, Santos EMS, Lima LVS, Miranda LN, Vasconcelos EL, Nagliate PC. Saberes docentes sobre processo ensino-aprendizagem e sua importância para a formação profissional em saúde. Interface - Comun Saúde, Educ [Internet]. 2016 [acesso em: 27 nov. 2017];20(57):437-48. Disponível em: http://dx.doi.org/10.1590/180757622014.1177.

8. Parecer CNE/CES no 1.133/2001, aprovado em 7 de agosto de 2001 (BR) [Internet]. Diretrizes Curriculares Nacionais dos Cursos de Graduação em Enfermagem, Medicina e Nutrição. Diário Oficial da União. 03 out. 2001 [acesso em: 27 nov. 2017]; Seção 1E, p. 131. Disponível em: http://portal.mec.gov.br/dmdocuments/ces1133.pdf.

9. Souza ER, Minayo MCS, Njaine K, Cruz AJM, Silvia, HB, Santos FCL, et al. Tendências da produção científica brasileira sobre violências e acidentes na década de 90. In: Minayo MCS, Souza ER. Violência sob o olhar da saúde: a infrapolítica da contemporaneidade brasileira. Rio de Janeiro: Editora Fiocruz; 2003. p. 49-81.

10. Lefèvre F, Lefèvre AMC. Depoimentos e discursos: uma proposta de análise em pesquisa social. $1^{\mathrm{a}}$ ed. Brasília: Liber Livro, 2005.

11. Moscovici S. The new magical thinking. Public Underst Sci [Internet]. 2014 [acesso em: 27 nov. 2017];23(7):759-79. Disponível em: http://dx.doi.org/10.1177/0963662514537584.

12. Beccaria G, Beccaria L, Dawson R, Gorman D, Harris JA, Hossain D. Nursing student's perceptions and understanding of intimate partner violence. Nurse Educ Today [Internet]. 2013 [acesso em: 27 nov. 2017];33(8):907-

11. Disponível em: http://dx.doi.org/10.1016/j.nedt.2012.08.004.

13. Gomes N, Erdmann AL, Higashi GDC, Cunha KS, Mota RS, Diniz NMF. Preparo de enfermeiros e médicos para o cuidado à mulher em situação de violência conjugal. Revista Baiana de Enfermagem [Internet]. 2012 [acesso em: 27 nov. 2017];26(3):593-603. Disponível em: https://portalseer.ufba.br/index.php/enfermagem/article/view/6754. 14. Bagnato MHS. Recontextualização curricular no ensino de enfermagem. Currículo sem Fronteiras [Internet]. 2012 [acesso em: 27 nov. 2017];12(3):173-89. Disponível em:

http://www.curriculosemfronteiras.org/vol12iss3articles/bagnato.pdf.

15. MacDonnell C, George P, Nimmagadda J, Brown S, Gremel K. A Team-Based Practicum Bringing Together Students Across Educational Institutions and Health Professions. Am J Pharm Educ [Internet]. 2016 [acesso em: 27 nov.

2017];80(3):49. Disponível em: https://doi.org/10.5688/ajpe80349.

16. Alba MV. Lo comunitario en las representaciones sociales de la violencia. Psicol Soc [Internet]. 2016 [acesso em: 27 nov. 2017];28(3):494-504. Disponível em: http://dx.doi.org/10.1590/1807-03102016v28n3p494.

17. Elston MA, Gabe J. Violence in general practice: a gendered risk? Sociol Health IIIn [Internet]. 2016 [acesso em: 27 nov. 2017];38(3):426-41. Disponível em: http://dx.doi.org/10.1111/1467-9566.12373.

18. Rocha BD, LanderdahI MC, Cortes LF, Vieira LB, Padoin SMM. Violence against women: Perceptions of nursing students' about the focus on the formation. Investig y Educ en Enfermería [Internet]. 2015 [acesso em: 27 nov. 2017];33(2). Disponível em: http://dx.doi.org/10.17533/udea.iee.v33n2a08.

19. Scherer ZAP, Scherer EA, Rossi PT, Vedana KGG, Cavalin LA. Manifestação de violência no ambiente universitário: o olhar de acadêmicos de enfermagem. Rev. Eletr. Enf. [Internet]. 2015 [acesso em: 27 nov. 2017];17(1):69-77. Disponível em: http://dx.doi.org/10.5216/ree.v17i1.22983.

20. Paim AS, lappe NT, Rocha DLB. Métodos de enseñanza utilizados por docentes del curso de enfermería: enfoque en la metodología de investigación. Enfermería Glob [Internet]. 2015 [acesso em: 27 nov. 2017];14(1):136-52.

Disponível em: http://dx.doi.org/10.6018/eglobal.14.1.186291. 
21. Baragatti DY, Audi CAF, Melo MC. Abordagem sobre a disciplina violência em um curso de graduação em enfermagem. Revista de Enfermagem da UFSM [Internet]. 2014 [acesso em: 27 nov. 2017];4(2):470-7. Disponível em: http://dx.doi.org/10.5902/2179769211265.

22. Waterkemper R, Prado ML. Estratégias de ensino-aprendizagem em cursos de graduação em Enfermagem. av. enferm. [Internet]. 2011 [acesso em: 27 nov. 2017];29(2):234-46. Disponível em:

http://www.scielo.org.co/scielo.php?script=sci arttext\&pid=S0121-45002011000200003\&lng=pt.

23. Sobral FR, Campos CJG. Utilização de metodologia ativa no ensino e assistência de enfermagem na produção nacional: revisão integrativa. Rev Esc Enferm USP [Internet]. 2012 [acesso em: 27 nov. 2017];46(1):208-18. Disponível em: http://dx.doi.org/10.1590/S0080-62342012000100028.

24. Bitencourt JVOV, Toldo MP, Schuck D, Schmatz L, Martini JG, Silva TG, et al. O processo de ensino aprendizagem adotado em uma Universidade Federal: visão dos estudantes de enfermagem. Revista de Teorias e Práticas Educacionais [Internet]. 2015 [acesso em: 27 nov. 2017];7(1):5-13. Disponível em:

http://www.mastereditora.com.br/periodico/20150811_170557.pdf.

25. Scherer ZAP, Scherer EA. Identificação dos pilares da educação na disciplina integralidade no cuidado à saúde. Rev Esc Enferm USP [Internet]. 2012 [acesso em: 27 nov. 2017];46(4):985-93. Disponível em:

http://dx.doi.org/10.1590/S0080-62342012000400029. 